\title{
A esquistossomose no Brasil após quase um século de pesquisas
}

\author{
Schistosomiasis in Brasil after one century of research
}

Zilton A. Andrade ${ }^{1}$

\begin{abstract}
Resumo Uma tentativa para se julgar da importância das pesquisas sobre esquistossomose, feitas no Brasil, desde 1908 até hoje, revela quão difícil e imprecisa é esta tarefa quando são postos em prática os critérios com que a produção científica é hoje em dia avaliada. Todavia, sem desmerecer a grande importância da contribuição internacional, os conhecimentos gerados sobre a esquistossomose no Brasil, neste quase um século de pesquisas, aparecem suficientes para atender a todas as nossas necessidades práticas e cientificas no setor.
\end{abstract}

Palavras-chaves: Schistosoma mansoni. Esquistossomose. Pesquisas no Brasil.

Abstract An attempt to evaluate the importance of scientific research on Schistosomiasis in Brazil, since 1908 until now, reveals the difficulties and uncertaunties of such a task, when current criteria for measuring scientific impact are employed. However, with due respect to the contribution of international research, the data originated from Brazilian research on schistosomiasis, during almost a century, now appear sufficient for dealing with all our pratical and scientific needs in this area.

Key-words: Schistosoma mansoni. Schistosomiasis. Brazilian research.

A literatura acumulada ao longo de quase um século pode ser revista pela exaustiva compilação feita pela Profa. Eurydice Pires de Santana em 1994, bem como pela listagem das teses sobre esquistossomose organizada pelo Grupo de Estudo da Esquistossomose da Fundação Oswaldo Cruz. Também, na análise da bibliografia internacional realizada sob a orientação de Kenneth S. Warren. Evidente que as limitações e, sobretudo, os pontos fracos desta análise estão na dependência do meu julgamento pessoal, embora o mesmo esteja baseado num interesse continuado, de quase meio século, sobre as pesquisas em esquistossomose.

Chego agora à etapa da comunicação aos colegas sobre o resultado da minha análise com um misto de satisfação e dúvidas. Satisfação em constatar que os pesquisadores brasileiros de fato contribuíram decisivamente para o conhecimento da esquistossomose ao longo deste tempo histórico. Aqui se acumulou uma experiência ímpar no mundo sobre a doença e seus agentes, hoje restando apenas detalhes, mais ou menos de interesse acadêmico, uma parte que é comum a todos os assuntos da ciência. Desde os primeiros trabalhos, as pesquisas sobre esquistossomose no Brasil tiveram um cunho prático, objetivo e multidisciplinar. Raramente aparecem entre os inúmeros trabalhos consultados, aqueles que têm um cunho meramente especulativo ou que refletem apenas modismos, sem objetivos claramente definidos.

A história se inicia no ano de 1908, quando Pirajá da Silva publica no Brasil-Médico o seu primeiro trabalho sobre o encontro do parasita na Bahia, 56 anos depois que Theodor Bilharz escreveu uma carta do Cairo, ao seu professor na Alemanha, dando conta do achado de um novo helminto parasita do homem.

No ano de 1908, os primeiros seis trabalhos sobre o assunto foram publicados, todos na Bahia, todos na revista Brasil-Médico, sendo 4 de autoria de Pirajá da Silva, um de Carvalho e outro de Froes. Estes trabalhos davam notícias da ocorrência da esquistossomose no Brasil e, no último que foi publicado naquele ano, Pirajá faz uma avaliação sobre os primeiros 20 casos humanos observados. Trata-se pois, de trabalhos que mostravam a existência da doença no Brasil, suas manifestações

\footnotetext{
1. Centro de Pesquisas Gonçalo Moniz da Fundação Oswaldo Cruz. Salvador, BA

Endereço para correspondência: Dr. Zilton Araújo Andrade. Centro de Pesquisas Gonçalo Moniz/FIOCRUZ. R. Valdemar Falcão 121, Brotas, 40295-001 Salvador, BA

Tel: $5571356-4320$

e-mail:zilton@cpgm.fiocruz.br

Recebido para publicação em 14/08/2001.
} 
clínicas, seu diagnóstico, bem como as características da espécie do parasito em questão, o que veio a ter repercussão internacional, dado o significado para a consolidação da espécie Schistosoma mansoni. Logo a seguir vêm as investigações sobre a distribuição geográfica da doença, depois das célebres viagens de exploração científica que os pesquisadores do Instituto Oswaldo Cruz costumavam fazer pelo interior do Brasil. Sobretudo os trabalhos de Lutz, de 1916 até os primeiros anos da década de 30 , além de dados gerais parasitológicos, vieram mostrar que a esquistossomose se constituía num importante problema de saúde pública. Estes dados foram consolidados mais tarde pelos relatórios de Pellon e Teixeira em 1950 e 1955.

Embora esta análise seja sobre significado e tendências e que, para evitar injustas omissões, tenha me proposto a não mencionar nomes de pesquisadores, gostaria de citar Heraldo Maciel e Luiz Tavares. Eles foram pioneiros que, com metodologia simples, fizeram perguntas pertinentes e escreveram vários trabalhos nas décadas de 30 e 40, preocupados, sobretudo, com as manifestações clínicas e o tratamento médico e cirúrgico dos pacientes. Simbolizam o interesse, a persistência e a objetividade do pesquisador brasileiro da época. A partir de 1950 as pesquisas mostraram um crescimento exponencial. Acredito que este fato se correlacione com o fenômeno da progressiva urbanização da população brasileira ocorrida no pós II Guerra Mundial (Figura 1). As pesquisas se fazem principalmente nas Universidades, que se localizam nas grandes cidades. Como as Universidades raramente vão ao interior, a esquistossomose veio às cidades, tornando

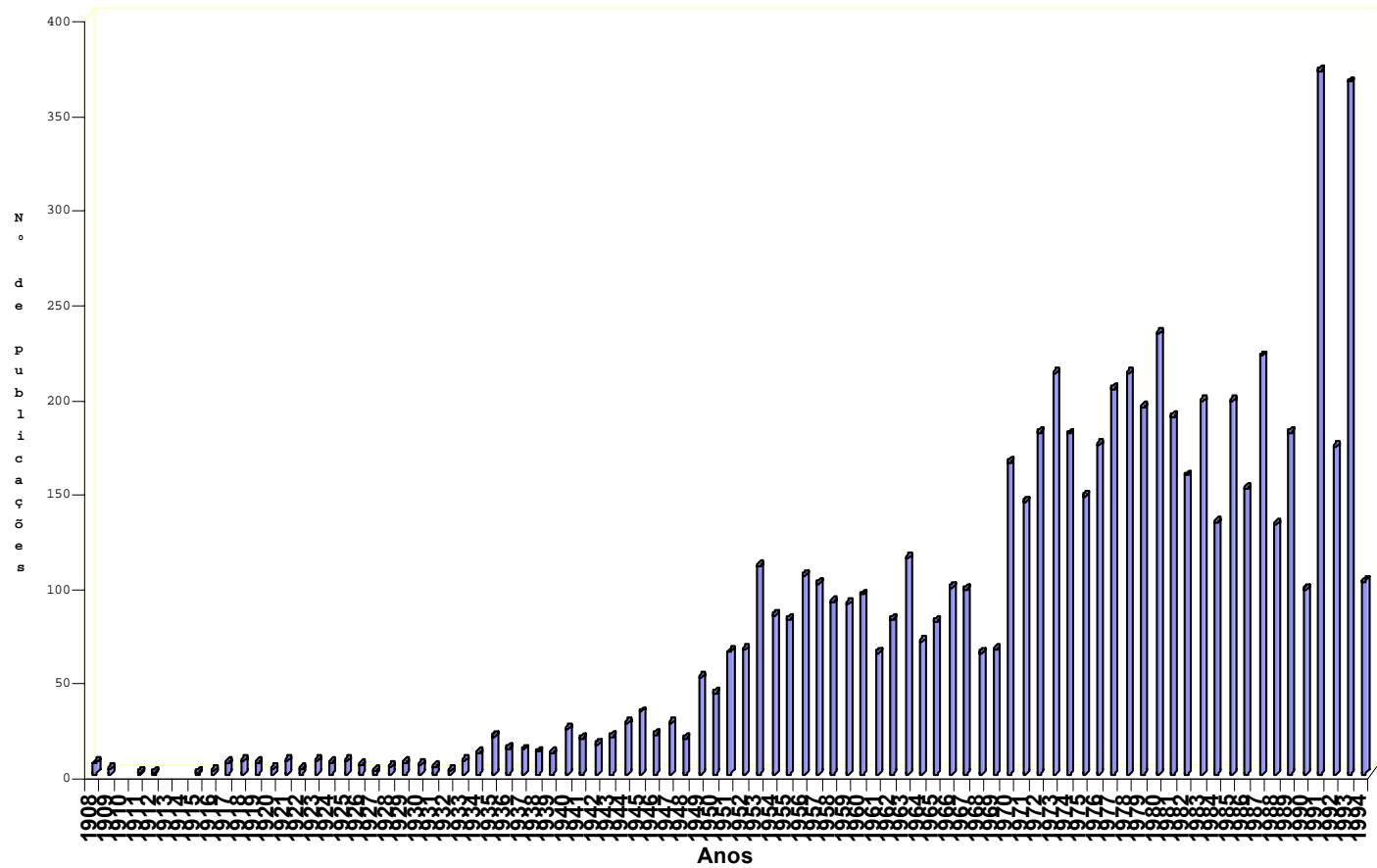

Figura 1 - Publicações sobre esquistossomose no Brasil. Período de 1908 a 1994.

mais visível um problema rural, que se tornava também peri-urbano. Os pacientes com as formas graves da esquistossomose surgiram em grande numero nas nossas enfermarias e despertaram considerável interesse nos nossos pesquisadores. As contribuições que apareceram em Revistas, em Teses de Livre Docência e de Cátedra, desde a década de 30 até o fim da década de 50, trouxeram aportes valiosíssimos para o conhecimento da clínica, do tratamento médico e cirúrgico, do diagnóstico, das associações mórbidas. Estes dados foram se consolidando subseqüentemente e hoje podemos recorrer aos conhecimentos criados no Brasil para abordar qualquer aspecto da clínica, patologia, epidemiologia, evolução, controle e tratamento da esquistossomose.

Ao lado das pesquisas clínicas se desenvolveram desde o início estudos parasitológicos sobre o parasito e seus hospedeiros intermediários cujo significado e profundidade nos surpreendem hoje. A biologia dos hospedeiros intermediários foi exaustivamente estudada. As espécies de Biomphalaria, suas localizações geográficas, seus predadores, sua susceptibilidade ou resistência ao S. mansonie as correlações destes dados com a doença humana, tudo foi escrutinado no imenso território brasileiro. 
Mais recentemente, as pesquisas com modelos experimentais se ampliaram e têm respondido questões práticas, tais como, resistência aos esquistossomicidas, reversibilidade das lesões após tratamento, influência de fatores nutricionais, patogenia da forma hepatoesplênica etc, bem como têm abordado importantes aspectos, de caráter mais acadêmico, sobre a patogenia das lesões hepáticas, pulmonares, esplênicas e renais, a participação do sistema imune na patogenia e na imunoprofilaxia, etc. Estes temas e outros vêm mais modernamente servindo como estímulo para o desenvolvimento da ciência brasileira, ajudando decisivamente no treinamento e na formação de novos pesquisadores, no intercâmbio com colegas estrangeiros, em várias áreas da medicina e da biologia. Para uma melhor visão deste assunto, passemos uma vista d'olhos sobre o que tem sido a produção de teses sobre o tema (Tabelas 1 e 2). Numa perspectiva destes estudos podemos visualizar a importância para o fomento e o intercâmbio que o Programa de Esquistossomose da FIOCRUZ e os seus Simpósios Internacionais têm trazido.

\begin{tabular}{lc} 
Tabela 1 - Teses sobre esquistossomose Brasil (1909 a 2000). \\
\hline Mestrado & 371 \\
Doutorado & 180 \\
Outros & 61 \\
\hline Total & 612 \\
\hline Computadas pelo Programa de Esquistossomose da FIOCRUZ
\end{tabular}

\begin{tabular}{lc} 
Tabela 2 - Temas principais das teses brasileiras sobre esquistossomose. \\
\hline Medicina Tropical (Clínica) & 159 \\
Hospedeiros Intermediários & 93 \\
Imunologia & 71 \\
O Parasito (Estudos experimentais) & 67 \\
Bioquímica & 57 \\
Diagnóstico e Terapêutica & 46 \\
Patologia & 30 \\
Epidemiologia & 43 \\
Parasitologia & 37 \\
O Parasito (Usado como modelo) & 09
\end{tabular}

Estas constatações positivas trouxeram-me grande satisfação. As dúvidas surgiram quando pretendi investigar, de uma maneira mais objetiva, o valor real da contribuição brasileira. Como medir? Este é um assunto de grande importância para nós. Um desafio principalmente colocado diante do pesquisador brasileiro atual, que escolheu pesquisar sobre doenças parasitárias, que afetam grandes contingentes das nossas populações carentes. Estamos sujeitos a sistemas de avaliação que são aplicados para trabalhos, seja de clínica, de cirurgia ou das ciências básicas, como bioquímica, fisiologia, farmacologia, etc. Vacilações sobre nossas prioridades de concentração de esforços nos causam angústia quando nos envolvemos com problemas básicos de imunologia, genética, patologia geral, tendo a esquistossomose como modelo. Sabemos que a Ciência é universal. Se Pasteur já dizia que a ciência não tem pátria, hoje com as comunicações instantâneas com qualquer lugar do mundo, suas palavras adquirem um significado ainda mais verdadeiro. Temos que adotar padrões internacionais para avaliar a nossa produção científica. Mas, como em tudo mais, não podemos fazê-lo de modo automático, acrítico. É bom que nos lembremos que, se a Ciência não tem Pátria, o cientista a tem. Ao julgar os trabalhos sobre esquistossomose na perspectiva do tempo, o enfoque não deve ser apenas na metodologia sofisticada empregada, nem na língua em que o trabalho foi escrito, mas na estrutura geral do trabalho em relação com a pergunta que se pretendeu responder. Temos que avaliar a contribuição trazida para o avanço dos nossos conhecimentos em geral, para a compreensão dos mecanismos da doença, do seu diagnóstico preciso, do seu tratamento, da sua profilaxia, do seu controle no particular. Vejamos algumas alternativas que se nos oferecem para que possamos avaliar quase um século de pesquisas em esquistossomose no Brasil.

Para muitos, particularmente para os avaliadores dos Cursos de Pós Graduação da CAPES, o importante é que haja trabalhos escritos em inglês, publicados em revistas indexadas, o que é um eufemismo para significar revistas estrangeiras. A grande maioria dos trabalhos da nossa literatura sobre esquistossomose, que tantos progressos trouxeram ao nosso conhecimento, acha-se escrita em português. É óbvio que os trabalhos escritos em inglês atingem um público 
mais amplo, que existe uma competição muito maior quando se pretende publicar nas boas revistas estrangeiras. Mas, nada pode ser tomado em sentido absoluto. A política editorial das boas revistas internacionais privilegia a metodologia sofisticada, 0 assunto em moda. Desculpem a irreverência, mas hoje em dia todos sabemos que uma bobagem acompanhada de técnicas de biologia molecular, de animais transgênicos, com KO de citocinas ou de moléculas de adesão tem mais chances de ser aceita do que uma um achado significativo demonstrado com métodos convencionais. Em outras palavras, seria desejável que nós, que não temos compromissos com a indústria da ciência, tivéssemos a maturidade para analisar os nossos trabalhos pelo seu valor intrínseco, pelo menos tendo a paciência de ler o título, o resumo e analisando as tabelas, gráficos e figuras. Esta é a maneira que estou acostumado a fazer e assim tenho constatado que há trabalhos bons e ruins escritos em qualquer língua, utilizando metodologias sofisticadas ou não e publicados em qualquer revista.

Outros procuram julgar a produção científica pela constatação dos efeitos que as pesquisas científicas teriam tido no combate à doença e na melhoria da saúde das nossas populações. Ủma maneira tão difícil quão equivocada de julgar pesquisas. Ela poderia satisfazer aqueles que estão mais próximos das decisões por prioridades políticas, mas que não as tomam, e que costumam cobrar dos cientistas a resolução dos problemas sociais e de saúde pública. Muitos aqui se recordam de que na época da ditadura militar, em que a sociedade brasileira vivia polarizada politicamente, a direita considerava o cientista como um subversivo, a esquerda o achava vendido ao capital internacional e o centro afirmava que ele não servia para nada, pois ainda não havia descoberto a cura das nossas principais doenças parasitárias. Hoje sabemos que a esquistossomose já não é mais o que costumava ser a até poucos anos atrás. As temíveis formas graves e suas complicações praticamente desapareceram dos nossos Hospitais. Todavia estes argumentos também não serviriam para julgar o valor das nossas pesquisas, pois muitos poderiam argumentar que o grande impacto sofrido pela esquistossomose no Brasil se deveu à descoberta de novas drogas curativas pelos laboratórios farmacêuticos estrangeiros e à melhoria geral do nosso ambiente rural, com modificações no sistema de distribuição de água e a adoção de algumas obras de engenharia sanitária.

Finalmente, consideremos a praxe em voga de se avaliar a produção científica pelo índice de citação, ou seja, contando quantas vezes os trabalhos foram citados por outros. Além de envolver um critério muito controvertido, seria uma tarefa quase impossível para se aplicar à produção brasileira de quase um século. Podemos todavia nos socorrer do excelente trabalho coordenado por Kenneth Warren. Ele verificou que, entre 1852 a 1972 (110 anos) foram publicados em todo o mundo 10.286 trabalhos sobre a esquistossomose em 1.738 diferentes revistas, por 6.511 autores, em 27 línguas. Para se ter uma idéia da produtividade brasileira na área, na bibliografia organizada por Eurydice Santana constam 6.816 trabalhos brasileiros entre 1908 e 1994 (86 anos).

O interessante a respeito do trabalho de Warren é que ele enviou a lista bibliográfica para diversos especialistas internacionais e solicitou que cada um apontasse os melhores trabalhos nas suas respectivas áreas, pois os mesmos seriam resumidos e re-publicados numa coletânea, como de fato foi. Em seguida, selecionou os que foram mencionados 4 ou mais vezes pelos especialistas. Assim, terminaram selecionados 404 trabalhos ou seja, $0,4 \%$ do total. Cerca de $2 / 3$ dos trabalhos não foram mencionados, sequer uma única vez! Mas, enquanto apenas $44 \%$ de toda a literatura estava em inglês, $86 \%$ de todos os trabalhos selecionados estavam nessa língua, o que revela a importância da língua inglesa na divulgação dos trabalhos científicos (Tabela 3). Os

\begin{tabular}{lr} 
Tabela 3 - A Equistossomose na Bibliografia Internacional (1852-1962). \\
\hline Total de trabalhos $\left(\mathrm{n}^{\circ}\right)$ & 10.286 \\
Diferentes revistas & 1.738 \\
Autores & 6.511 \\
Línguas & 27 \\
Trabalhos Selecionados por um Comitê de & \\
Especialistas de Diferentes Nacionalidades & $404(0,4 \%)$ \\
Trabalhos escritos em Inglês & $44,0 \%$ \\
Selecionados & $86,0 \%$ \\
Trabalhos escritos em português & $13,5 \%$ \\
Selecionados & $2,3 \%$
\end{tabular}

trabalhos que apareceram em português atingiam 13,5\% do total e destes foram selecionados 2,3\%. Após analisar cuidadosamente este resultado, considerei o mesmo como altamente positivo para a avaliação da pesquisa brasileira em esquistossomose. Primeiro, a pesquisa de
Warren incluiu apenas uma fração dos trabalhos brasileiros. Depois, vários trabalhos brasileiros foram publicados em inglês e alguns deles aparecem selecionados. (Tabelas 1,2 e 3). Mas, o que considero importante constatar é que os selecionadores, na sua 
grande maioria, provinham de países não endêmicos. Todos eram comprovadamente competentes, tinham vivido ou visitado áreas endêmicas da doença. Todavia, na minha opinião, um pesquisador igualmente competente, que nasceu e se criou vendo o problema tem geralmente uma idéia diferente sobre prioridades e abordagens que acabam influenciando os resultados de uma pesquisa do tipo da que fez o Warren. De qualquer maneira, as inferências que possamos fazer sobre os dados colhidos por Warren e a situação após quase um século das nossas pesquisas sobre esquistossomoses têm valor muito relativo, pois nada foi planejado com esta finalidade.

No que pesem as dificuldades para uma avaliação mais precisa, terminei a minha incursão por este quase século de pesquisas com a impressão que a área de esquistossomose se constitui em uma das mais desenvolvidas da ciência médica brasileira, tanto em quantidade, quanto em qualidade e, repito, nela predominou a abordagem prática, objetiva e multidisciplinar. Creio que entre as doenças endêmicas no Brasil, somente a doença de Chagas, pode rivalizar com o porte das pesquisas em esquistossomose.

Para o futuro as pesquisas em esquistossomose na área aplicada procurarão responder sobre métodos combinados de controle da transmissão, sobre possibilidade de ocorrência de formas graves, sobre quimioterapia com novas drogas, possibilidades e avanços dos métodos de imagem, refinamento de técnicas diagnósticas em regiões de baixa endemicidade, significado clínico da glomerulopatia associada à esquistossomose, associação com a hepatite viral, etc. Do lado das pesquisas básicas, os pós graduandos vão continuar a contar com excelentes perspectivas de pesquisas experimentais e de intercâmbio nas áreas de patologia, biologia e imunologia, seja em hospedeiros definitivos ou intermediários. Os jovens pesquisadores brasileiros em esquistossomose devem estar conscientes de que há um grande acerco de informações aqui obtidas, desde quase um século, para apoiar os seu estudos. 